\title{
Acute lung injury in fulminant hepatic failure following paracetamol poisoning
}

\author{
Simon V Baudouin, Peter Howdle, John G O'Grady, Nigel R Webster
}

\begin{abstract}
Background - There is little information on the incidence of acute lung injury or changes in the pulmonary circulation in acute liver failure. The aim of this study was to record the incidence of acute lung injury in fulminant hepatic failure caused by paracetamol poisoning, to document the associated pulmonary circulatory changes, and to assess the impact of lung injury on patient outcome.
\end{abstract}

Methods - The degree of lung injury was retrospectively assessed by a standard scoring system (modified from Murray) in all patients with fulminant hepatic failure caused by paracetamol poisoning, admitted to the intensive care unit over a one year period. The severity of liver failure and illness, other organ system failure, and patient outcome were also analysed.

Results - Twenty four patients with paracetamol-induced liver failure were admitted and nine developed lung injury of whom eight (33\%) had severe injury (Murray score $>2 \cdot 5$ ). In two patients hypoxaemia contributed to death. Patients with lung injury had higher median encephalopathy grades (4 $v 2$ in the noninjured group) and APACHE II scores (29 $v$ 16). Circulatory failure, requiring vasoconstrictor support, occurred in all patients with lung injury but in only $40 \%$ of those without. Cerebral oedema, as detected by abnormal rises in intracranial pressure, also occurred in all patients with lung injury but in only $27 \%$ of the noninjured patients. The incidence of renal failure requiring renal replacement therapy was similar in both groups $(67 \%$ and 47\%). Pulmonary artery occlusion pressures were normal in the lung injury group. Cardiac output was high (median 11.21/ min), systemic vascular resistance low

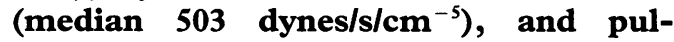
monary vascular resistance low (median 70 dynes $/ \mathrm{s} / \mathrm{cm}^{-5}$ ), but not significantly different from the group without lung injury. Mortality was much higher in the lung injury group than in the non-injured group $(89 \% v 13 \%)$.

Conclusions - Acute lung injury was common in patients with paracetamol-induced fulminant hepatic failure and was associated with systemic circulatory failure and cerebral oedema. The development of acute lung injury was associated with high mortality.

(Thorax 1995;50:399-402)

Keywords: lung injury, liver failure, paracetamol.
Paracetamol poisoning is the commonest cause of fulminant hepatic failure in the UK and causes approximately 250 deaths per annum. ${ }^{1-3}$ In severe cases there is rapid progression to multisystem failure with changes occurring in the peripheral circulation, brain, and kidneys. It is probable that changes in systemic vascular control cause the progression to multiorgan failure $^{4}$ with reductions in systemic vascular resistance, decreased renal blood flow, and changes in cerebral blood flow having been reported..$^{3-10}$ Despite the common occurrence of failure in other organ systems, there is very little information on changes in the lung and pulmonary circulation in acute liver failure.

Acute respiratory failure was described as a complication of fulminant hepatic failure by Trewby and colleagues ${ }^{11}$ who found that 37 of 100 consecutive patients admitted to a specialist liver failure unit with acute liver failure developed pulmonary problems. Limited haemodynamic data were available in 12 patients, all of whom had a normal pulmonary artery occlusion pressure which suggested that the lung oedema was caused by lung injury.

Recent research has improved our understanding of the pathophysiology of acute lung injury ${ }^{1213}$ and some agreement has been reached on the definition of the disease and scoring of severity. ${ }^{1415} \mathrm{We}$ have retrospectively surveyed the incidence of acute lung injury in fulminant hepatic failure, caused by paracetamol poisoning, using a well established scoring system to grade the degree of lung injury. ${ }^{14}$ We also correlated the severity of lung injury with the degree of liver failure, with changes in pulmonary and systemic haemodynamics, and with the extent of other organ failure.

\section{Methods}

The study was retrospective in design and included all patients with fulminant hepatic failure (as defined by Trey and Davidson ${ }^{16}$ ) caused by paracetamol poisoning and admitted to the intensive care unit at St James's University Hospital between 1 January 1992 and 31 December 1992. Clinical information was obtained by review of the computerised intensive care unit data base, the daily intensive care observation sheets, patient case notes, and review of plain chest radiographs by one author who was unaware of individual patient outcome. The severity of liver encephalopathy was graded using a standard score as follows: grade 1 , drowsiness; grade 2, increased drowsiness and confusion; grade 3, marked confusion and agitation but responding to simple commands; 
Table 1 Components and individual values of the lung injury score

\begin{tabular}{|c|c|}
\hline & Value \\
\hline $\begin{array}{l}\text { (1) Chest radiograph score } \\
\text { No alveolar consolidation } \\
\text { Alveolar consolidation confined to } 1 \text { quadrant } \\
\text { Alveolar consolidation confined to } 2 \text { quadrants } \\
\text { Alveolar consolidation confined to } 3 \text { quadrants } \\
\text { Alveolar consolidation in all } 4 \text { quadrants }\end{array}$ & $\begin{array}{l}0 \\
1 \\
2 \\
3 \\
4\end{array}$ \\
\hline $\begin{array}{l}\text { (2) } \mathrm{Hypoxaemia} \text { score }\left(\mathrm{PaO}_{2} \text { in } \mathrm{mm} \mathrm{Hg}\right) \\
\mathrm{PaO}_{2} / \mathrm{FIO}_{2}>300 \\
\mathrm{PaO}_{2} / \mathrm{FIO}_{2} 225-229 \\
\mathrm{PaO}_{2} / \mathrm{FIO}_{2} \quad 175-224 \\
\mathrm{PaO}_{2} / \mathrm{FIO}_{2} \quad 100-174 \\
\mathrm{PaO}_{2} / \mathrm{FIO}_{2}<100\end{array}$ & $\begin{array}{l}0 \\
1 \\
2 \\
3 \\
4\end{array}$ \\
\hline $\begin{array}{l}\text { (3) Respiratory compliance score (when available) } \\
\text { Compliance }>80 \mathrm{ml} / \mathrm{cm} \mathrm{H}_{2} \mathrm{O} \\
\text { Compliance } 60-79 \mathrm{ml} / \mathrm{cm} \mathrm{H}_{2} \mathrm{O} \\
\text { Compliance } 40-59 \mathrm{ml} / \mathrm{cm} \mathrm{H}_{2} \mathrm{O} \\
\text { Compliance } 20-39 \mathrm{ml} / \mathrm{cm} \mathrm{H}_{2} \mathrm{O} \\
\text { Compliance }<19 \mathrm{ml} / \mathrm{cm} \mathrm{H}_{2} \mathrm{O}\end{array}$ & $\begin{array}{l}0 \\
1 \\
2 \\
3 \\
4\end{array}$ \\
\hline
\end{tabular}

The final value is obtained by dividing the aggregate sum by the number of components that were used:

$\begin{array}{ll}\text { No lung injury } & \text { Score } \\ \text { Mild to moderate lung injury } & 0 \\ \text { Severe lung injury } & 0 \cdot 1-2.5 \\ & >2.5\end{array}$

grade 4, comatose and unrousable. Lung injury was assessed on a daily basis using a modification of the Murray scoring system ${ }^{14}$ (table 1). Plain chest radiographs and oxygenation data were available for all patient and lung compliance data for nine of the 16 ventilated cases. A lung injury score of more than $2 \cdot 5$ indicated severe lung injury. The severity of illness on admission to the intensive care unit was graded using the APACHE II scoring system. ${ }^{17}$ Statistical comparisons between groups were made using the rank sum test.

\section{Results}

Twenty four patients were admitted to the intensive care unit in 1992 with hepatic failure

Table 2 Prognostic factors (median and range) for the 24 patients with hepatic failure

\begin{tabular}{lcc}
\hline Description & Median value or total & Range \\
\hline Hepatic coma score on initial admission & 3 & $2-4$ \\
Worst hepatic coma score during admission & 4 & $2-4$ \\
APACHE II score & 26 & $9-24$ \\
pH on admission & $7 \cdot 30$ & $6 \cdot 92-7 \cdot 52$ \\
Number with pH $<7 \cdot 3$ & 10 & $35-195$ \\
Maximum prothrombin time (s) & 88 & $69-572$ \\
Number with a prothrombin time $>100 \mathrm{~s}$ & 10 & \\
Serum creatinine level on admission to ITU $(\mu \mathrm{mol} / \mathrm{l})$ & 206 & 12 \\
Number with serum creatinine $>300 \mu \mathrm{mol} / 1$ & 12 & \\
\hline
\end{tabular}

Table 3 Prognostic factors and outcome in the group with no lung injury and those with lung injury

\begin{tabular}{llll}
\hline & $\begin{array}{l}\text { No lung injury } \\
(n=15)\end{array}$ & $\begin{array}{l}\text { Lung injury } \\
(n=9)\end{array}$ & \multicolumn{1}{c}{$p$} \\
\hline Median hepatic coma score on admission & 2 & 4 & $0 \cdot 01$ \\
Median APACHE II score & 16 & 29 & $<0.05$ \\
Mean prothrombin time (s) & 87 & 92 & NS \\
Percentage with pH <7.3 & 33 & 67 & NS \\
Number requiring renal replacement therapy & 7 & 6 & NS \\
Mean (SD) serum albumin (g/l) & $34(4)$ & $34(7)$ & $<0.001$ \\
Mortality (\% of total group) & $2(13 \%)$ & $8(89 \%)$ & \\
\hline
\end{tabular}

NS = not significant. following paracetamol poisoning. The patients were predominantly young (mean age 32 ) and 15 were women. They presented to emergency departments at a time following paracetamol ingestion (range 12-56 hours) when $\mathrm{N}$-acetylcysteine is much less effective in preventing liver damage. ${ }^{18}$ All patients were referred for intensive care within 72 hours of original admission and most within 48 hours.

PROGNOSTIC FACTORS (table 2)

Seventeen patients progressed to grade 3 or 4 hepatic coma during their admission. Ten patients fulfilled the poor prognostic category of $\mathrm{O}^{\prime}$ Grady and colleagues ${ }^{2}$ with either marked metabolic acidosis on admission ( $\mathrm{pH}<7 \cdot 3$ ), or grade III or worse encephalopathy, a peak prothrombin time of more than 100 seconds, and a creatinine level on admission above $300 \mu \mathrm{mol} / \mathrm{l}$.

\section{TREATMENT DURING THE INTENSIVE CARE} ADMISSION

All patients received $N$-acetylcysteine and a gut decontamination regimen during their admission. In addition all patients who were not in established renal failure received a low-dose dopamine infusion. Central venous pressure was monitored in all patients and 19 had full haemodynamic monitoring by balloon flotation pulmonary artery catheters with thermodilution recordings of cardiac output. Intracranial pressure was monitored in 16 patients by extradural systems and the same 16 required mechanical ventilation. In 14 cases this was initiated because of hepatic encephalopathy. In two patients hypoxaemia $\left(\mathrm{PaO}_{2}<8 \mathrm{kPa}\right.$ on an $\left.\mathrm{FIO}_{2}>0.7\right)$ was also an important factor in initiating ventilation. Sixteen patients required vasopressor support (noradrenaline or angiotensin II) and 13 required renal replacement therapy (pumped venovenous haemofiltration) during admission. One patient underwent emergency orthotopic liver transplantation.

LUNG INJURY (table 3)

Eight patients developed severe lung injury (Murray score $>2.5$ ) during admission and one patient developed mild to moderate injury with a mean score of 1 . The average time from ingestion of paracetamol to maximum lung injury was 106 hours (range 55-151 hours). Patients who developed lung injury were more severely ill, as judged by higher hepatic coma and APACHE II scores, and more had metabolic acidosis and renal failure. Serum albumin levels were normal in the patients with lung injury. Mortality was much higher in the lung injury group (89\%) than in the group without injury $(13 \%)$. Major causes of death included cerebral oedema (eight), hypotension (seven), hypoxaemia (two), and bacterial sepsis (one). A combination of factors was present in many patients. 
Table 4 Median (range) values of the most abnormal systemic and pulmonary haemodynamics recorded in the 10 patients with paracetamol poisoning and no lung injury and in the nine patients with lung injury

\begin{tabular}{lcc}
\hline & $\begin{array}{l}\text { No lung injury } \\
(n=10)\end{array}$ & $\begin{array}{l}\text { Lung injury } \\
(n=9)\end{array}$ \\
\hline Right atrial pressure $(\mathrm{mm} \mathrm{Hg})$ & $9(-3$ to 15$)$ & $10(+5$ to 13$)$ \\
Pulmonary artery pressure $(\mathrm{mm} \mathrm{Hg})$ & $22(12$ to 26$)$ & $21(15$ to 30$)$ \\
Pulmonary vascular resistance $\left(\right.$ dynes $\left./ \mathrm{s} / \mathrm{cm}^{-5}\right)$ & $61(24$ to 138$)$ & $70(28$ to 100$)$ \\
Pulmonary artery occlusion pressure $\left(\mathrm{mm} \mathrm{Hg}^{-}\right)$ & $11(5$ to 16$)$ & $10(3$ to 12$)$ \\
Mean arterial pressure $(\mathrm{mm} \mathrm{Hg})$ & $81(58$ to 122$)$ & $73(66$ to 104$)$ \\
Systemic vascular resistance $\left(\right.$ dynes $\left./ \mathrm{s} / \mathrm{cm}^{-5}\right)$ & $514(500$ to 620$)$ & $503(387$ to 660$)$ \\
Cardiac output $(1 / \mathrm{min})$ & $10.6(9.8$ to $11 \cdot 5)$ & $11.2(10.0$ to $19 \cdot 4)$ \\
\hline
\end{tabular}

No significant difference in pulmonary or systemic haemodynamics was seen between the two groups.

SYSTEMIC AND PULMONARY HAEMODYNAMICS (table 4)

Full haemodynamic measurements were made in 19 patients, including all the patients with lung injury. Pulmonary artery occlusion pressures were normal in both the groups with and without lung injury. Systemic vascular resistance was reduced in the group as a whole and in the subgroup with lung injury, and cardiac output was increased. Pulmonary artery pressures were mildly increased in the patients with lung injury but pulmonary vascular resistance was low. There was no significant difference between pulmonary or systemic haemodynamics in the two groups.

\section{LUNG INJURY AND ORGAN FAILURE}

The incidence of raised intracranial pressure (as judged by a rise of at least $25 \mathrm{~mm} \mathrm{Hg}$ for five minutes) was higher in the group with lung injury $(100 \%$ v $27 \% ; \mathrm{p}<0.001)$, and the incidence of circulatory failure (as assessed by the need for vasoconstrictor support) was also higher in the same group $(100 \%$ v $40 \%$; $\mathrm{p}<0.001)$. The incidence of renal failure requiring renal replacement therapy was similar in both groups ( $67 \% v 47 \%)$.

\section{MICROBIOLOGY}

Blood cultures were positive in one patient with lung injury (Staphylococcus aureus was grown). Sputum cultures and tracheal aspirates were negative in this group.

\section{Discussion}

There was a high incidence $(33 \%)$ of acute lung injury, as judged by the Murray lung injury score, in this group of patients. In eight of the nine with lung injury the injury was severe, and in two patients intractable hypoxaemia contributed to death. There is little information concerning the respiratory complications of fulminant hepatic failure. Lucke and Mallory, in $1946,{ }^{19}$ reported pulmonary oedema in five of 18 patients who died of liver failure caused by infectious hepatitis, and Kunelis $e t a l^{20}$ found that three out of 16 patients with acute fatty liver of pregnancy developed pulmonary oedema. Experience of 100 consecutive patients admitted with fulminant hepatic failure (37 caused by paracetamol poisoning) to a specialist liver unit published in 1978 by Trewby et al predated current definitions of acute lung injury and used plain chest radiographic criteria alone to judge the presence of pulmonary oedema. ${ }^{11}$ On this definition $37 \%$ developed signs of lung injury including $41 \%$ in the group with paracetamol poisoning. We have used a scoring system developed by Murray and coworkers ${ }^{14}$ to assess the presence and severity of lung injury and found an incidence of severe lung injury of $33 \%$, similar to that found by Trewby et al using their broader definition. The original system included a score for the level of positive and expiratory pressure (PEEP). We have not included this factor as we deliberately avoided the use of PEEP in acute liver failure because of its possible adverse effects on intracranial pressure. Lung injury was so severe in eight of the nine patients that it is unlikely that the addition of PEEP would have significantly reduced the injury score.

The development of lung injury was associated with a poor outcome and only one patient survived the intensive care admission compared with an $87 \%$ survival in patients without injury. This differs from the findings of Trewby et al where the development of radiological pulmonary oedema did not adversely affect outcome. Differences in the severity of liver failure may explain the contrasting findings, as the series studied by Trewby et al only included patients with grade 4 hepatic encephalopathy whilst the current series also included patients with less severe encephalopathy.

It is possible that the lung injury was caused by either a direct cytotoxic effect of paracetomol metabolites on the lung ${ }^{1}$ or a result of raised intracranial pressure. ${ }^{21}$ However, the significant overlap between the development of lung, brain, and circulatory problems suggests that they are caused by the same mechanism. Endotoxaemia is a potent cause of acute lung injury $^{22}$ resulting in raised pulmonary vascular resistance with normal pulmonary artery occlusion pressures. ${ }^{232}$ Although pulmonary artery occlusion pressures were normal in the group with lung injury, supporting the hypothesis that the pulmonary interstitial and alveolar space filling process was caused by an increase in pulmonary vascular permeability, pulmonary vascular resistance was reduced despite the use of vasoconstrictors to support the systemic circulation. This important difference in the pulmonary haemodynamics of lung injury in acute liver failure and sepsis may indicate that endotoxaemia was not the cause of the lung damage.

Excessive production or lack of clearance of an endogenous systemic and pulmonary vasodilator could explain the circulatory changes and organ oedema in acute liver failure. Vallance and Moncada have hypothesised that, in liver failure, circulating endotoxins and cytokines induce the synthesis of the endogenous vasodilator nitric oxide which produces the characteristic changes in circulatory control. ${ }^{25}$ The experimental administration of vasodilators increases microvascular leak, ${ }^{26}$ and the production of an endogenous systemic and pulmonary vasodilator (possibly nitric oxide ${ }^{25}$ ) could explain the occurrence of both the cir- 
culatory disturbances and cerebral and pulmonary oedema observed in acute liver failure.

Many patients with paracetamol-induced fulminant hepatic failure develop severe lung injury. This group is characterised by the development of severe hypotension with cerebral oedema and has a very high mortality. The overlap between the development of circulatory, cerebral, and respiratory failure suggests that a common factor, possibly an endogenous vasodilator, is responsible for the changes.

1 Bray GP. Liver failure induced by paracetamol. BMF 1993 ; 306:157-8.

2 O'Grady JG, Alexander GJM, Hayllar KM, Williams R. Early indicators of prognosis in fulminant hepatic failure. Gastroenterology 1989;97:439-45.

3 O'Grady JG, Williams RS. Acute hepatic failure. In: Tinker J, Zapol WM, eds. The care of the critically ill patient. London: Springer-Verlag, 1991;609-20.

4 Wendon JA, Harrison PM, Keays R, Gimson AE, Alexander GJM, Williams R. Effects of vasopressor agents and epoprostenol on systemic haemodynamics and oxygen transport in fulminant hepatic failure. Hepatology 1992;15: 1067-71.

5 Bihari DJ, Gimson AES, Williams R. Disturbances in cardiovascular and pulmonary function in fulminant hepatic vascular and pulmonary function in fulminant hepatic
failure. In: Williams $\mathrm{R}$, ed. Liver failure. Edinburgh: Churchill Livingstone, 1986:47-71.

6 Blei AT. Cerebral edema and intracranial hypertension in acute liver failure: distinct aspects of the same problem. Hepatology 1991;13:376-9.

7 Blendis LM. Circulation in liver disease. Transplant Proc 1993;25:1741-3

8 Colombato LA, Albillos A, Groszmann RJ. Temporal relationship of peripheral vasodilation, plasma volume expansion and the hyperdynamic circulatory state in portalpansion and the hyperdynamic circulatory stat
hypertensive rats. Hepatology 1992;15:323-8.

9 Almdal T, Schroeder T, Ranek L. Cerebral blood flow and liver function in patients with encephalopathy due to acute and chronic liver diseases. Scand $\mathcal{f}$ Gastroenterol 1989;24 299-303.

10 Harrison PM, Wendon JA, Gimson AES, Alexander GJM,
Williams R. Improvement by acetylcysteine of hemodynamics of oxygen transport in fulminant hepatic failure. N Engl f Med 1991;324:1852-7.

11 Trewby PN, Warren R, Contini S, Crosbie WA, Wilkinson SP, Laws JW, et al. Incidence and pathophysiology of pulmonary edema in fulminant hepatic failure. Gastroenterology 1978;74:859-65.

12 Repine JE. Scientific perspectives on adult respiratory distress syndrome. Lancet 1992;339:466-9.

13 Spragg RS, Smith RM. Biology of acute lung injury. In: Crystal RG, West JB, eds. The Lung: Scientific Foundations. New York: Raven Press, 1991:2003-17.

14 Murray JF, Matthay MA, Luce JM, Flick MR. An expanded definition of the adult respiratory distress syndrome. $A m$ Rev Respir Dis 1988;138:720-3.

15 Bernard GR, Artigas A, Brigham KL, Carlet J, Falke K, Hudson L, et al. Report of the American-European consensus conference on ARDS: definitions, mechanisms, relevant outcomes and clinical trial coordinations. Intensive Care Med 1994;20:225-32.

16 Trey C, Davidson C. The management of fulminant hepatic failure. In: Popper H, Schaffner F, eds. Progress in liver on diseases. Vol 3. New York: Grune and Stratton, 1970: 292-8.

17 Knaus WA, Draper EA, Wagner DP, Zimmerman JE. APACHE II: a severity of disease classification system. Crit Care Med 1985;13:818-29.

18 Keays $R$, Harrison PM, Wendon JA, Forbes A, Gove C, Alexander GJM, et al. Intravenous acetylcysteine in paracetamol induced fulminant hepatic failure: a prospective acetamol induced fulminant:303:1026-9. a prospective of

19 Lucke B, Mallory T. The fulminant form of epidemic hepatitis. Am F Pathol 1946;22:867-945.

20 Kunelis CT, Peter JL, Edmondson HA. Fatty liver of pregnancy and its relation to tetracycline therapy. $A m \mathcal{F} M e d$ 1965;38:359-77.

21 Malik AB. Mechanisms of neurogenic pulmonary edema. Circ Res 1985;57:1-18.

22 Rounds SIS. Pulmonary circulatory control in lung injury. In: Weir EK, Reeves JT, eds. Pulmonary vascular physiology and pathophysiology. New York: Marcel Decker, 1989: and parth

23 Brigham KL Meyrick B. Endotoxin and lung injury. $\mathrm{Am}$ Rev Respir Dis 1986;133:913-27.

24 Leeman $M$. The pulmonary circulation in acute lung injury: a review of some recent advances. Intensive Care Med 1991;17:254-60.

25 Vallance P. Moncada S. Hyperdynamic circulation in cirrhosis: a role for nitric oxide? Lancet 1991;337:776-8

26 Warren JB. Vascular control of inflammatory oedema. Clin Sci $1993 \cdot 84 \cdot 581-4$. 